\title{
METHODS OF COOPERATIVE LEARNING AND THEIR APPLICATION IN THE DEVELOPMENT OF COMPETITIVE THEMES IN TEACHING MATHEMATICS
}

\author{
Desa Ilić \\ BSc Mathematics and Physics Matijevac, University in Brcko, Bosnia and Herzegovina, \\ Vladimirci, Serbia \\ E-mail: desarilic@gmail.com
}

\begin{abstract}
APA Citation: Ilić, D. (2018). Methods of cooperative learning and their application in the development of competitive themes in teaching mathematics. Indonesian Journal of Learning and Instruction, 1(2), 1-10.
\end{abstract}

\begin{abstract}
In modern school, children need to play a central role. It should become a place where they are exploring, examining, solving problems and to lead them to a deliberate dialogue. Students need to experience the school as a place where the child develops in cognitive, emotional and social sense, where the child's motivation to work is at a high level. An active school is more focused on a young man who is treated as a whole person whose intellectual potentials need to engage more in the teaching process. The active school is based on compulsory education standards based on which the orientation plans and work programs are designed. Such access also implies a part of teaching that is flexible and varies depending on the student's interest. In teaching, active learning methods are based on work and intellectual engagement of students and research activities. The goal of an active school is not only the adoption of a curriculum, but also the versatile personality development of students. The active school evaluates not only the degree of competence of the knowledge defined by the educational standards, but also the progress of the children in comparison with the initial situation, the motivation and interest of the students for work and activity, the development of the personality and the satisfaction of the student's teaching that is realized.
\end{abstract}

Keywords: mathematics; learning; co-operation; classes.

\section{INTRODUCTION}

Cooperative learning is the topic of a large number of research both in the world and in our country. The focus of these researches is on achievements, interpersonal relationships and mental health. Participants in research differ according to age, ability, gender, race, nationality, socio-economic status etc. Different tasks, models and techniques of cooperation were used. Research has been conducted by researchers of different theoretical orientations in different conditions and over a long period of time. This research, in addition, has such validity and trust, which can be rarely found in pedagogical and psychological literature.

In the broadest sense, cooperative learning can be defined as any learning situation in a classroom where students of all levels of achievement work in structured groups to achieve a common goal. Cooperative learning is also defined as the use in teaching small groups where students work together to achieve the maximum, both their own and the groups they work with. In these groups they are negotiating, initiating, planning and evaluating each other. Instead of working individually and competing with each other, students are responsible for building a community in which all students participate. Co-operative learning requires that students work together to achieve goals that as individuals do not achieve. Students involved in cooperative learning have many social and academic benefits.

The experience of cooperation and the interactive exchange of information that occurs during cooperative learning has the 


\section{Desa Ilić}

Methods of cooperative learning and their application in the development of competitive themes in teaching mathematics

consequence of having a better memory of teaching contents, improving attitudes towards learning and strengthening interpersonal relationships among group members.

Teachers should try to create a class organization that will encourage student interaction with the goal of mutual cooperation. Co-operation and interaction among children can be encouraged by the introduction of collaborative groups. In the following, we will present several models of collaborative groups, i.e. ways of organizing student work in the teaching of mathematics (Rešić, 2016).

The aim of cooperative learning is to advance each and every student, in different aspects, such as achievement, social skills, self-confidence, etc. After participating in cooperative work, the members of the group should be trained to do the same or similar task independently.

Cooperative learning in teaching mathematics, only a small number of researchers have carefully examined specific types of interactions that occur among students while learning math in smaller groups. Most of the interaction-related tasks identified among students are related to the help they seek or provide to each other (Gušović, 2013).

A great deal of concern among mathematicians is encountering the low recognition of students that they need help in learning math. Neumann and Goldin (1990) show that children, especially with lower opportunities, are reluctant to seek help when they have difficulties in learning math. They are most reluctant to seek help from their friends, mostly because of being afraid they will laugh at them. If they are to seek help, their main source is a teacher who is often unable to provide the appropriate assistance each pupil needs individually. Carefully designed subdivisions to smaller groups can enable interaction between students who, in turn, can provide appropriate assistance to the pupils who need it.
Unfortunately, most math lessons do not sufficiently promote student activity in tasks. What is more, full-time, as an environment in which students are not sufficiently active, has shown negative effects of low student achievement (Mulyn, 1992). By contrast, some small cooperative learning groups have shown that student work is increased and student interaction facilitated learning in small groups does not ensure automatic collaboration in work and positive effects in all students. For example, sometimes more capable learners by showing far more active behavior tend to dominate the less able learners. Although promoting math through co-operation in small groups makes it feasible for "highly productive students", the real challenge remains to do the same with "low productivity" students.

The most commonly applied levels or forms of realization of cooperative learning in the teaching of mathematics are: 1) Cooperative learning based on the department; 2) Cooperative learning based on small groups, subgroups or teams; 3) Cooperative learning based on couples.

In cooperative learning based on the department are suitable for certain stages of work, such as: talk breaks used for discussion and active student learning, for introducing into a topic or problem, when discussing topics that are just present for discussion, asking questions, and interplay help with the materials that are just exposed. While, cooperative learning based on small groups, subgroups or terms take place when small groups of students work on a common task that can only be solved by cooperation of all group members. The group work represents the sitting of students in smaller groups of 3 to 6 students. The best group of 4 students, because that communication is six-fold. Group composition can be permanent or changeable. Then, cooperative learning based on couples has long been considered that learning in pairs is nothing more than learning in the smallest group. Working in pairs (tandem) is a transitional model of individual to more complex forms of work. We can say that work in couples is 
an innovative form of work in the contemporary teaching. By working in pairs, the students get better and the climate for work is more enjoyable, the student's activity is maximized, as feedback is even more encouraging for the activity. The student is trained to compare his work as well as to listen patiently to the interlocutor. This mode of work also has some shortcomings, such as restriction, rivalry, more time to get feedback on student work, etc. The solution needs to be sought in understanding the pair as a temporary form of joint work on a task or part of a task.

\section{METHOD}

Anyone who had ever tried to organize a cooperative lesson from any subject knew that it was not easy, because it was necessary that the time was so designed to provide an active participation of all students.

Some of the leading pedagogues in this area had devised methods used by teachers around the world. Some of these methods were taken from contemporary literature in this paper, some I had taken from the seminar "To Functional Knowledge Using Methods and Techniques in Interactive Teaching", and some were just ideas that need to be thoroughly considered. The aim was to provide teachers with as many methods as possible and more recent knowledge in this field. Of course, in applying this method it was possible to perform combinations or create an analogous own approach, depending on the specific conditions of teaching practice and teacher training. It had been shown that these methods develop apart from achievement, and cooperative quality of personality, favorable emotional climate in learning and a higher level of student motivation. The most important advantage of cooperative learning methods was their compatibility with traditional teaching. The teacher, therefore, did not have to abandon his previous experiences. Practice had shown that whoever tries these methods would definitely decide to continue to use them and would not go back to the old.
The mosaic method was one of the first strategies of cooperative learning. It was originally developed by Eliot Aronson and his colleagues at the University of Texas. Aronson had developed a mosaic method to address some of the school segregation problems of the 1970s in the United States when they were separated in black and white studs and there was very little interaction between pupils of different skin colors. Aronson has solved this problem by involving students in small, heterogeneous groups with a division of tasks and sources in which the pupils are doing so that each student has to rely on all the members of the group. This interdependence of the students was very high, and the role of the teacher as a provider of information was temporarily diminished.

The name "mosaic" expresses the essence of this cooperative learning strategy. The learning material was distributed to members of the group in the form of mosaics and a piece was given to members of the group. The zeal that was generated by the slicing of the material would not be solved until all the pieces are put together. In essence, the responsibility of each member of the team was to process their piece of material and to teach the other. In other words, the mosaic method firmly binds pupils of materials and resources, as well as strongly motivated the interdependence of students in cooperative learning. A team member who was not efficient in the work on his or her piece of work can help other members of the team.

Although it was originally developed for the fifth and sixth grades of elementary school, the mosaic method can be applied for work in all grades of primary school, and children need to be able to read because most tasks in the mosaic method require a minimum reading ability. In the original mosaic method the students work in two groups: a control group (expert group) working together to produce a joint material and a mosaic group (the so-called homegroup) working on material that had just been learned from each group member 


\section{Desa Ilić}

Methods of cooperative learning and their application in the development of competitive themes in teaching mathematics

individually in expert groups. The original mosaic method required each mosaic group member to be part of one of the control groups working on the teaching material. The members of the control group had the same number of different mosaic groups. They work on the same teaching material, study information, discuss the method for working on the material. When the mosaic of the group was rebuilt, each student taught others about his material he learned in his control group. While the mosaic method strongly relied on the task and resources as well as on the interdependence of group members, it was important to point out that this was essentially not a hierarchical method. The method did not require the same level of mastery for all students. Usually, students master the material that, as experts, convey to their mosaic group.

It was recommended to reduce the number of members of mosaic groups, depending on the number of topics for work. Team members could be selected so that one organizer-leader was found in each group for each mosaic group. It was important that the group organizer helped the group and forms the role of a team leader for other students in the group (because all must play that role). After two to three meetings, the roles of the team leader rotate and each mosaic group chooses a new leader. To be experts in their field, pupils were composed of members of the same mosaic groups who had the same questions, the same thing. The members of the matched or expert groups work together to understand the material, and discuss how it was easier to master that piece to make the most of it to its mosaic group. Approximately $30 \%$ of time was spent on treating materials in the expert group. It was recommended that the leader of a mosaic group choose pre-work. If all the material was matched and done at the same level, it was possible to enable students in the expert groups who had completed their task to help others in their work on the design, as well as developing the ways of doing it themselves. In these circumstances, each expert group must be as heterogeneous as the mosaic group.

When they finish learning in expert groups, students returned to their mosaic groups to teach others the curriculum, as specially arranged, if possible. Members of the group mosaic considered the material to ensure that each member understands. When the group ended up with the learning material, the time for discussion, analysis, and reflection followed. Proportionally, it is necessary to spend $60 \%$ of the time on the curriculum and $40 \%$ on the discussion. When they finish working in mosaic groups, students take individual tests and materials. The interaction task used in the mosaic method is to ensure that each student was fully successful on an individual test. This success depends on the individual's cooperation. Aronson and his associates did not foresee any form of reward within this method.

\section{RESULTS AND DISCUSSION}

This was the teaching unit with which students of the eighth grade of elementary schools meet. The very concept of treating the information was known to the students, both from the earlier classes and from life. This teaching unit was also a good proof that math is everywhere around us and that it was a very applicable science. There was also an opportunity to acquire functional (applicable) knowledge in which it is specifically insisted.

One example of this was when students were given data gathered in a survey and they were subdivided into expert groups first to learn how to process and display data (drawing tables, graphs, diagrams) and then return to their mosaic groups and train other students to present together files.

We divided the students into groups of 4 students and each group gets a special assignment. Namely, the students had visited the tourist destinations of our region as part of the project of learning geography and collected data on the number of visitors, number of foreigners, age structure, number of visitors in certain periods of the year and 
Indonesian Journal of Learning and Instruction Volume 1, Issue 2, October 2018

so on. Now, at the math class, students received the data they were supposed to process and show to some of the statistical methods. Each group got one tourist destination.

The students pulled out one card marked with a number from 1 to 4 . Then the students with the same number on the card formed the group. Then the captains of the groups form an expert group that had two tasks to learn how to make graphs and diagrams based on data written in the table using one of the Word tools and then teach other members of its mosaic group. When they finish learning in their expert groups, students return to their mosaic groups. Each of the mosaic members of the group was obliged to transfer the knowledge they had acquired to the other members in order to ensure that each member understands. When the group had finished the learning material, it was time for questions, analysis, thinking, etc. After completing the work in mosaic groups, each student got tasks to work individually. Depending on the interaction within the group used in the mosaic method, each student would achieve some result on the individual test. If the group work was successful and the students cooperated with each other, then the results on the test would be as good as possible.

\section{Method of scoring-achievement}

This method had emerged as a practical application of learning theorists of motivation achievement. The essence of applying the scoring method was that the students know exactly what they were looking for, that they had time to prepare and that there were no surprise factors in checking the adopted knowledge.

After processing the teaching unit, students were given points for mastering the teaching contents. Points were given analytically. Any information, fact, or essential item was scored in brackets beside content with a predefined number of points, so that the students knew how much points they were going to get by filling out this information. At the end of the teaching unit
p-ISSN 2614-8250, e-ISSN 2614-5677

https://journal.uniku.ac.id/index.php/IJLI

or topic, a score scale was awarded (for example, 21 points for grade 2, 31 for good and the like). The student did not know which questions would be on the test or on the test of knowledge.

Points - Achievement was very effective for group work. The class was divided into groups that were preparing for a few days or weeks to test the lessons learned. Group collaboration was followed. All members of the group were concerned that each group learner learns the best to make the group more successful. It was possible to organize various forms of competition between groups. The differences between the other cooperative methods and this were that the students know exactly what was being sought for the grade, and that grade would not be different from the teachers.

When working on teaching contents, the teacher should draw the student's attention to important information and scoring. It is best to give the teaching unit a test question. In addition to which it was indicated where the answers are in the book or other source of knowledge, as well as how many points they carry. The teacher could use multiple forms of evaluation of achievement, depending on their assessment of the effects of this evaluation.

This type of evaluation should be applied which would most contribute to the further achievement of students:

Testing individual achievement when group work is used: the goal was to establish a group's achievement, and individual student contributions were valued only by a group. It is an important group assessment. A group rating was highlighted in a class chart, in a school newspaper or otherwise. It was important that a group is struggling for more achievement by training or "training" all its members for maximum individual scores;

Evaluating group achievement without individual scoring: the goal was to test groups rather than individuals. Testing for the group needs to be prepared.

Self-assessment of the group: The goal was to show the group's achievements in the 


\section{Desa Ilić}

Methods of cooperative learning and their application in the development of competitive themes in teaching mathematics

curriculum and analyze the way to achieve the achievement.

\section{Method of group research}

Methods of group research had been developed by Sharan and Herz- Lazarowitz (Sharan and Hertz-Lazarowitz, 1980; Sharan and Sharan, 1992) as a variation of the project method. Topics could be suggested by students based on search by source or by self-propagation topic. Groups of 5 to 6 students are formed that would study the topic of their choice. The composition of the group is based on the theme selection. Each group discusses its topic and analyzes the aspects of a possible approach to the topic.

The first three questions should be answered first:

What will we do?

How will we do it?

Why will we do it?

Subsequently, the group conducts it was research plan, which implies defining tasks for each member of the group. Group members searched for sources of knowledge to better respond to the project assignment. Each group member should be aware that a better outcome of each individual will also mean a better result for the group. Each group should select one member for the Steering Board. The task of this committee was to monitor the group's progress, to ensure that each member of the group is engaged, to hear the group's plans for the final report, to draw up a list of final presentations and to consider the needs of each group. The whole group presented what it had done so that every member of the group had its role in the final report. The teacher helps students who did not know how to present their material. The entire class should be in good standing during the presentation of any group. It would be desirable for the presentations to include a part that points to difficulties in processing or investigating problems, as well as instruction to other students as best to overcome the topic considered.

The teacher was starting to evaluate during the observation of the students' work in the groups. It was necessary to evaluate how students had approached the subject and the problem of research, how they cognitively treated and which skills did they use. It was necessary to involve students in evaluation as much as possible or to develop self-evaluation. The Steering Board should be a group work assessor, but it was very important to carry out the evaluation of this committee's work. For the evaluation, the teacher could create a "group efficiency questionnaire" that would be filled out by all the students and processed by the board of directors.

Students should be divided into 5 groups of heterogeneous compositions with approximately equal number of members. Each of the groups would deal with one of the following budget items:

Foods and beverages,

Chemical products

Home Appliances and Applied

Techniques

Wardrobe

Monthly Accounts (Taxes)

The groups could agree on which items would be responsible or items may be assigned by a random selection method, for example by pulling the cedar from the hat.

Before going to the survey, each student should ask their parents who were working in the family, how often they went shopping, which foods they bought every day, what was in their opinion necessary to bought within the items the student belonged to and the monthly invoices. When students met in a group, it was necessary to share the knowledge they had come to and to make a list of the things that were necessary for the life of a family. Their imaginative family must be equipped with as many basic things as possible. The goal was to save as much as possible. It was also necessary to elect the members of the board of directors from that group. The task of the first three groups was to visit great brands and find the catalogs with the reduced prices of the products that they need in accordance with their group and then calculated how much the percentage was their discount, how much money would 
Indonesian Journal of Learning and Instruction Volume 1, Issue 2, October 2018

be saved in such a purchase and write down in their reports.

If students lived in an environment where there were no large markets, these catalogs could be found in daily newspapers or discounts seen in TV commercials. Old catalogs could also be used, and the pupils could do it by going to the appropriate shops, for example the home appliance store, and writing down what was on the discount. Individual products must be found in the reports regardless of whether they were discounted because their purchase is indispensable for family life.

Thus, a group in charge of food products in their report must be obliged to include bread, dairy products, fruits and vegetables and other basic products with their prices if they were in the catalogs or not.

In the final report must be found all the products that the group "bought" with their prices with and without a discount, the total amount of money spent and how much of the percentages were saved by discounting.

As the wardrobe was rarely found in the catalogs, the group responsible for "dressing" the family had to go to the shops and on the face of the place find the reductions they mostly had throughout the year. The minimum wardrobe was a shirt, trousers or skirt, depending on the half, and shoes for each member individually.

The family, for example, consisted of four members: father, mother and two children. In the final report, all the wardrobes that the group had chosen to buy with their prices with and without discounts, the total amount of money spent and how much money was saved by discounting.

As for the group in charge of monthly households, their task was for each member of the group to collect information from their parents about the monthly bills for the previous month for items: electricity, telephone, cable, internet, etc. Based on the data of each group member, by calculating the mean value for each item, the monthly account of the imaginary family was obtained. Also, from talking to parents and studying accounts, the group should
p-ISSN 2614-8250, e-ISSN 2614-5677

https://journal.uniku.ac.id/index.php/IJLI

determine how much each account would be reduced if a payment was made to a specific date, or, if not, until the date was specified, how much would be the increase (interest) on these accounts. In the final report, all accounts should be found with their amounts if they were paid in time, to calculate how much savings had been made and what the costs would be if they were late for payment.

When all the groups complete their research, each group would say what it all included in their research, which they produced on the list, how they came to the price, what caused them problems and how much they had saved. For such a presentation, the group could choose to own a representative who did not have to be a member of the board of directors. When the presentations are over, the board of directors would meet, and based on the data that each member of the board would bring, it was calculated how much money was spent on the family (total budget), what was the final cost savings and what percentage of that total budget that group spent.

This information would be forwarded to each group by each member of the board, and all submissions would be completed by entering them.

\section{Co-operative concept mapping}

The "Cooperative map concept" method had been developed by a group of authors at the Concordia University in Montreal. The author's intention was to develop a method that would help students understand the subject matter with the help of their classmates. It had been noted that a large number of children equated memory with the understanding of the material. Practice had shown that children could easily explain some of their contents and ideas to each other in their own way, rather than what teachers do. When students learned to sketch and conceptualize their explanations, the effectiveness of these instructions increases. This method required students to plan and conceptualize their plan maps based on identifying the main ideas and links between them. It was a graphical seed, for example, a 


\section{Desa Ilić}

Methods of cooperative learning and their application in the development of competitive themes in teaching mathematics

node-junction-node, in which the contents of the idea are printed in nodes (rectangles and circles) and the links were represented by lines or arrows.

It was advisable for a teacher to bring out and demonstrate a concept map and explain it and give groups so that students saw a conceptual model that would later facilitate their learning and mapping.

Many students came to school with prejudices about learning and teaching, with the understanding that success was enough to memorize the facts. It also supported the beholder mode. To work efficiently in the map concept, students had to change their attitudes or prejudice about teaching. Learning objectives should be understood by students as their own.

It was necessary to form heterogeneous groups of 3 to 4 members and encourage them to cooperate and assist the weaker so they could lean onto the group. It was important for students to understand a cooperative mapping concept and to understand the conceptualization process. The teacher should make an emphasis on thinking out loud so that all students can follow the theses, main ideas, relationships between them and the like. Let the students understand that it was not only important to conceptualize the contents, but also to develop the ability to conceptualize. It was necessary that students have the courage to notice the main ideas, to learn to summarize the text and to know what is important. When each of the students drew their own idea into the notebook, the students in the groups discuss individual notes, ideas and theses. They ask each other questions and ideas. Groups reduced the number of ideas and make the key structure of the nodes from which the concept maps will be derived. It was necessary to encourage students to ask or consult teachers, if necessary. While explaining the folder to other members of the group, the student purifies his understanding of the material.

Students should be able to see the success of this work from a teacher's point of view, but should ask themselves to analyze what they had learned and how the mapping process was going on. Also, it was important for students to emphasize that it was not only the concept of folders that they were important but also the facilitations they made when memorizing content.

\section{CONCLUSION}

The fact is that the most efficient learning is what is happening in the group and that cooperation is the basis for any progress. When we separate people and individually evaluate, we make a gap between them and their natural environment.

The results of the research have shown that co-operative learning as an indicator of quality education and education is reflected in school climate, interaction and communication, improving interpersonal relationships, willingness to help and cooperate, friendships and peer acceptance, as well as their own contribution to learning and work. Pupils who have met cooperative learning point out the interestingness and usefulness of this learning, its contribution to relaxation and the overcoming of fears of negative evaluation and school failure.

However, although the review of the mentioned literature on cooperative learning provides a clear picture that its application in school provides very potent effects when student achievement and their social and emotional development, research on school practice shows that the application of individual work is still dominant in the teaching of basic and Secondary schools. One of the possible reasons for insufficient representation of cooperative learning in practice is the fact that initial attempts by teachers to create those situations among pupils are often condemned to failure. Teachers who do not have the resources and resources to plan and apply this form of work, apart from their enthusiasm and interest in trying something new with their students, are quickly disappointed because they are faced with serious problems in discipline and motivation of students. More careful insight into interaction models in groups reveals primers of a number of 
Indonesian Journal of Learning and Instruction Volume 1, Issue 2, October 2018

phonographs and the withdrawal of others. Given that they are not accustomed to cooperation while learning, students will rather retain patterns of behavior commonly used in individual forms of work. However, this does not have to discourage the teachers. Every teacher who has had at least one successful class and felt the benefits of such a method often returns to this modern method.

\section{REFERENCES}

Anić, I., Pavlović, B. D., \& Radak, V. (2011). Formula života: Za sve koji vole matematiku $i$ žele da je poklone drugima. Beograd: Matematiskop.

Aronson, E., Bridgeman, D.L., \& Geffner, R. (1978). The effects of a cooperative classroom structure on students' behaviour and attitudes. In D. BarTal, \& L. Saxe (Eds.), Social psychology of education: Theory and research. Washington DC: Hemisphere.

Davidson, N. (1990). Small-group cooperative learning in mathematics. In T. J.Cooney, \& C. R. Hirsh (Eds.), Teaching and learning mathematics in the 1990s, the 1990 yearbook of the national council of teachers of mathematics (pp.52-61). Reston, VA: National Council of Teachers of Mathematics.

De Zan, I. (2000). Metodika nastave prirode $i$ društva. Zagreb: Školska knjiga.

Dedic, H., Rosenfield, S., d'Apollonia, S., \& De Simone, C. (1994). Using Cooperative concept mapping in college science classes. Cooperative learning and college teaching, 4, 12-15.
p-ISSN 2614-8250, e-ISSN 2614-5677

https://journal.uniku.ac.id/index.php/IJLI

Ivan, I., Ana, P., \& Slobodanka, A. (2001). Aktivno učenje. Beograd: Institut za psihologiju and UNICEF.

Johnson, D. W., \& Johnson, R.T. (1994). Learning together and alone (4th ed.). Needham Heights, MA: Allyn and Bacon.

Kagan, M., Robertson, L. \& Kagan, S. (1995). Cooperative learning structures for classbuilding. San Clemente, CA: Kagan Cooperative Learning.

Mulryan, C. M. (1992). Student passivity during cooperative small groups on mathematics. Journal of Educational Research, 85, 261-273.

Newman, R. S., \& Goldin, L. (1990). Children's reluctance to seek help with schoolwork. Journal of Educational Psychology. 82(1), 92-100.

Piaget, J. (1975). Ou vas l'education. Paris: Denoel.

Rešić, S., \& Alma, Š. (2016). Metodika nastave matematike. Užice: Učiteljski fakultet.

Ruthven, K. (1987). Ability stereotyping in mathematics. Educational Studies in Mathematics, 18, 243-253.

Sharan, S., \& Hertz-Lazarowitz, R. (1980). A groupinvestigation method of cooperative learning in the classroom. In S. Sharan, P. hare, C. D. Webb, \& R. Hertz-Lazarowitz (Eds.), Cooperation in education. Provo, UT: Brigham Young University Press.

Ševkušić, S. (1995). Teorijske osnove i perspektive kooperativnog učenja. Zbornik instituta za pedagoška istraživanja, 27, 138-157. Beograd: Institut za pedagoška Istraživanja.

Webb, N. M. (1985). Student interaction \& learning in small groups: A research summary. In R. Slavin, S. Sharan, S. Kagan, R. HertzLazarowitz, C. Webb, \& R. Schmuck (Eds.), Learning to cooperate, cooperating to learn (pp. 147-172). New York: Plenum Press. 


\section{Desa Ilić}

Methods of cooperative learning and their application in the development of competitive themes in teaching mathematics 